TI 2013-089/VIII

Tinbergen Institute Discussion Paper

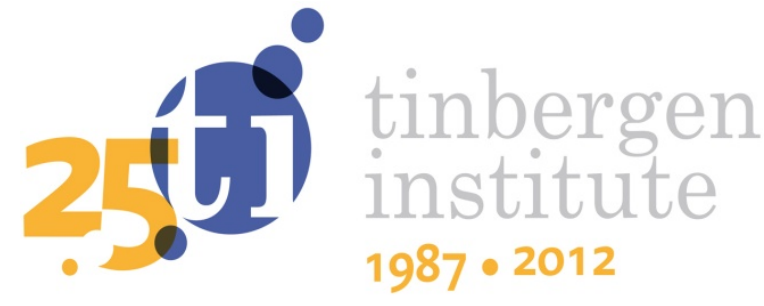

\title{
Road Congestion and Incident Duration
}

\author{
Martin W. Adler \\ Jos van Ommeren \\ Piet Rietveld
}

Faculty of Economics and Business Administration, VU University Amsterdam, and Tinbergen Institute. 
Tinbergen Institute is the graduate school and research institute in economics of Erasmus University Rotterdam, the University of Amsterdam and VU University Amsterdam.

More TI discussion papers can be downloaded at http://www.tinbergen.nl

Tinbergen Institute has two locations:

Tinbergen Institute Amsterdam

Gustav Mahlerplein 117

1082 MS Amsterdam

The Netherlands

Tel.: +31(0)205251600

Tinbergen Institute Rotterdam

Burg. Oudlaan 50

3062 PA Rotterdam

The Netherlands

Tel.: +31(0)10 4088900

Fax: $+31(0) 104089031$

Duisenberg school of finance is a collaboration of the Dutch financial sector and universities, with the ambition to support innovative research and offer top quality academic education in core areas of finance.

DSF research papers can be downloaded at: http://www.dsf.nl/

Duisenberg school of finance

Gustav Mahlerplein 117

1082 MS Amsterdam

The Netherlands

Tel.: +31(0)20 5258579 


\title{
Road congestion and incident duration
}

\author{
Martin W. Adler, Jos van Ommeren, Piet Rietveld \\ VU University Amsterdam \\ De Boelelaan 1105, 1081 HV Amsterdam, The Netherlands \\ Tinbergen Institute, Amsterdam \\ Gustav Mahlerplein 117, 1082 MS Amsterdam, The Netherlands
}

15 July 2013

\begin{abstract}
Non-recurrent congestion is frequently caused by accidents and other incidents. We estimate the causal effect of incident duration on drivers' time losses through changes in non-recurrent road congestion on Dutch highways. We demonstrate that incident duration has a strong positive, but concave, effect on non-recurrent congestion. The duration elasticity of nonrecurrent congestion is about 0.40 implying that a one minute duration reduction generates a $€ 60$ gain per incident. We also show that at locations with high levels of recurrent congestion, non-recurrent congestion levels are considerably higher. At very congested locations, the benefit of reducing the incident duration by one minute is about $€ 500$ per incident. Public policies that prioritize duration reductions at congested locations are therefore more beneficial.
\end{abstract}

Keywords: congestion, vehicle-loss-hours, incident duration, accidents

Acknowledgments: This paper is funded by Kennis voor Klimaat. We thank Damir Vukovic and Maaike Snelder, from TNO, for support in data acquisition and constructive remarks and Paul Fortuin from Rijkswaterstaat for funding. Furthermore, we thank the audience at Tinbergen Institute seminar, Amsterdam, and the 2013 NECTAR conference, Ponta Delgada, for constructive remarks. Jos van Ommeren and Piet Rietveld are fellows of the Tinbergen Institute. 


\section{Introduction}

Traffic congestion is an omnipresent phenomenon during rush hour in densely-populated regions (see, for example, Arnott and Small, 1994; Downs, 2004). We focus on non-recurrent congestion on highways, which is mostly caused by road accidents, and other types of incidents (e.g., object on road, car breakdown). ${ }^{1}$ This type of congestion constitutes roughly one-quarter of highway congestion (e.g., Snelder and Drolenga, 2011). In the current paper, we aim to estimate to what extent the level of non-recurrent congestion may be changed by public incident management policies and in particular by reducing the incident duration, i.e. the time it takes that all incident-associated traffic measures are lifted. Such measures include, for example, traffic warnings, speed reductions and lane closures. Lanes are seldom completely closed. For example, in the Netherlands, for $86 \%$ of incidents at least one lane is closed, but for only 8\% of incidents all lanes are closed (Snelder and Drolenga, 2011). Given an incomplete closure of lanes, the time loss for a driver due to an incident is much shorter than the incident duration. ${ }^{2}$ We assess the marginal costs of incident duration, distinguishing between the duration effects of accidents and other incidents.

Not only incident duration, but also traffic demand, and therefore recurrent congestion, determines non-recurrent congestion costs (for the literature on traffic demand and congestion, see, e.g., Beckmann et al., 1956; Goodwin, 2004; Small and Verhoef, 2007). The costs of non-recurrent congestion can be reduced through policies that shorten incident duration and re-establish traffic free flow. ${ }^{3}$ The incident duration reduction effectiveness has been discussed widely, see for example, Carson et al. (1999). This connection between duration and non-recurrent congestion is also discussed in Garrison and Mannering (1990), who use a traffic simulation model for highways in the Seattle urban area. They find that it an extremely congested location where three out of four lanes are closed, \$2,000 is lost in travel time for each additional minute of accident duration. Nam and Mannering (2000) show that the public agency that leads the responds to the incident (e.g., fire department or police) affects the length of the incident duration. ${ }^{4}$

\footnotetext{
${ }^{1}$ We define an incident as an 'irregular' occurrence on a highway, including objects on the road, car break downs, one-sided or two-sided accidents.

${ }^{2}$ Our data, discussed later on, suggest that the time loss is only 18 to $25 \%$ of incident duration.

${ }^{3}$ Incident duration studies often focus on the effects of incident characteristics on incident duration for specific highways, see, for example, Guiliano (1989) and Jones et al. (1991). These studies point out that incident duration depends on incident type and severity. We will see that the effect of incident duration almost fully captures the effects of incident characteristics on non-recurrent congestion.

${ }^{4}$ Lee and Fazio (2005) findings suggest that response time, i.e. the time it takes the incident manager to arrive at the location of an incident and clearance time, i.e. the crash-removing duration, are also a function of time and incident characteristics (e.g. severity, type of cars).
} 
We contribute to the literature by estimating the effect of incident duration on nonrecurrent congestion using microdata on incidents for the entire Dutch highway network. Importantly, in our estimation methodology, we take into account time-invariant, i.e. location, on a $100 \mathrm{~m}$ precision level, as well as time-varying road characteristics, such as the level of recurrent congestion. Furthermore, we deal with selection effects and endogeneity issues. Our results show that there is a strong positive, but concave, effect of incident duration on nonrecurrent congestion for accidents and other incidents.

\section{Data and descriptives}

Our data set comprises information on highway incidents from five types of road service providers (i.e., incident management organizations, towing companies, medical response teams, police and fire departments) for the years 2007 to 2009 for the entire Netherlands. ${ }^{5}$ We also use traffic flow data from the Ministry of Infrastructure and the Environment (RWS), weather information of the Royal Netherlands Meteorological Institute (KNMI) and precipitation radar information (Buienradar).

In our analysis, the dependent variable is the level of non-recurrent congestion as $a$ result of an incident. Most of the time, locations are incident free. However, at many locations traffic intensity may still regularly exceed road capacity and cause congestion. Hence, nonrecurrent congestion is the additional increase of congestion due to an incident in comparison to the 'normal' situation - i.e. recurrent congestion level - at a certain location and time of the day. For each incident, we have accurate estimates for the levels of non-recurrent and recurrent congestion, based on traffic intensity and speed data obtained from induction loops. Congestion levels are calculated at the time and location of the incident for the entire highway network. Therefore, our congestion measure includes both primary congestion, i.e. on the lane(s) of the incident, and secondary congestion, i.e. on the opposite lane and spillback on the connections to other highways. Primary non-recurrent congestion accounts for about 70\% of overall non-recurrent congestion ${ }^{6}$

Recurrent congestion is measured by the median weighted road congestion for each incident location and time of day, using an eight week window around the incident. To calculate the median, only observations within this window that are 'similar' to the time of the incident are included. To be precise, it includes the other six days of the week of the incident and the same day of the week for four weeks before and after the incident (congestion on the

\footnotetext{
${ }^{5}$ Figure A1 in the Appendix shows a map of the national Dutch highway network. For a minor number of highways with low traffic intensity (north of Amsterdam and west of Breda), data is not available.

${ }^{6}$ The congestion measurement methodology is discussed in more detail by Snelder and Drolenga (2011).
} 
day one week before and after the incident receives twice the weight). ${ }^{7}$ Non-recurrent congestion is calculated as the difference between total congestion and recurrent congestion. ${ }^{8}$ Congestion are measured in vehicle-loss-hours (VLH). ${ }^{9}$ Incident duration is measured in minutes from the time when the incident is registered by RWS (the road service provider) until the time all traffic measures associated with the incident are lifted.

Table 1 - Descriptives of incident features

\begin{tabular}{|c|c|c|c|c|c|}
\hline & \multicolumn{4}{|c|}{ Selected data set } & \multirow{2}{*}{$\begin{array}{c}\text { Full data set } \\
\text { (5) }\end{array}$} \\
\hline & $\begin{array}{c}(1) \\
\text { Positive } \\
\text { recurrent } \\
\text { congestion }\end{array}$ & $\begin{array}{c}(2) \\
\text { Positive } \\
\text { recurrent } \\
\text { congestion }\end{array}$ & $\begin{array}{c}\text { (3) } \\
\text { Positive } \\
\text { recurrent } \\
\text { congestion }\end{array}$ & $\begin{array}{c}(4) \\
\text { Zero } \\
\text { recurrent } \\
\text { congestion }\end{array}$ & \\
\hline & Accidents & Non-accidents & & & \\
\hline Non-recurrent congestion (VLH) & 449.6 & 367.1 & 424.9 & 61.1 & 62.1 \\
\hline Recurrent congestion (VLH) & 103.9 & 94.2 & 101.0 & 0 & 22.6 \\
\hline Incident duration (minutes) & 48.7 & 46.1 & 47.9 & 70.2 & \\
\hline Accident & 1 & 0 & 0.70 & 0.61 & 0.39 \\
\hline \multicolumn{6}{|l|}{ Type of vehicle involved } \\
\hline Passenger car & 0.60 & 0.38 & 0.53 & 0.47 & 0.41 \\
\hline Truck & 0.14 & 0.24 & 0.17 & 0.22 & 0.11 \\
\hline Motorcycle & 0.019 & 0.0050 & 0.015 & 0.010 & 0.0053 \\
\hline \multicolumn{6}{|l|}{ Type of damage } \\
\hline Injury and Fatality & 0.10 & 0 & 0.073 & 0.079 & 0.014 \\
\hline Severe material damage & 0.26 & 0 & 0.18 & 0.16 & 0.059 \\
\hline Number of observations & 6,506 & 2,788 & 9,294 & 2,352 & 263,185 \\
\hline
\end{tabular}

The full data set contains 263,185 incident observations of which about $40 \%$ are accidents, defined here incidents that involve a vehicle damage. ${ }^{10}$ Registration of incident duration by the agencies involved (e.g., incident management crew, police) was not obligatory during the period of observation. For only 11,646 observations, the incident duration is known. We select these observations. Among these, recurrent congestion is zero for 2,352 observations (about 20\% of the sample), but positive for 9,294 observations, see columns (3) and (4) in Table 1. We will focus on the latter group, because non-recurrent congestion levels are generally small when recurrent congestion is zero (see Table 1 , (4)). So, a positive level of recurrent congestion is generally a condition that non-recurrent congestion occurs. The selected data set is clearly not random. For example, the shares of accidents and of incidents

\footnotetext{
${ }^{7}$ For an example of how this median is calculated, see Table A1 in the Appendix.

${ }^{8}$ Non-recurrent congestion must be non-negative. However, due to limitations in the way recurrent congestion is approximated, non-recurrent congestion is negative in $0.02 \%$ of observations. We exclude these few observations.

${ }^{9}$ Hence, one car waiting in a traffic jam for one hour results in the same VLH as 60 cars delayed by one minute.

${ }^{10}$ We exclude observations when no information on type of incident (i.e., accident or no accident) is provided.
} 
with injuries and fatalities are larger in the selected data set (see Table 1). ${ }^{11}$ Plausibly, incident managers devote more attention to these incidents, increasing the likelihood of recording incident duration. ${ }^{12}$ In addition, the average levels of non-recurrent and recurrent congestion are five to six times larger in the selected data set, likely because locations and times with high traffic intensity are prioritized by road service providers. ${ }^{13}$

Figure 1 - Density of non-recurrent congestion

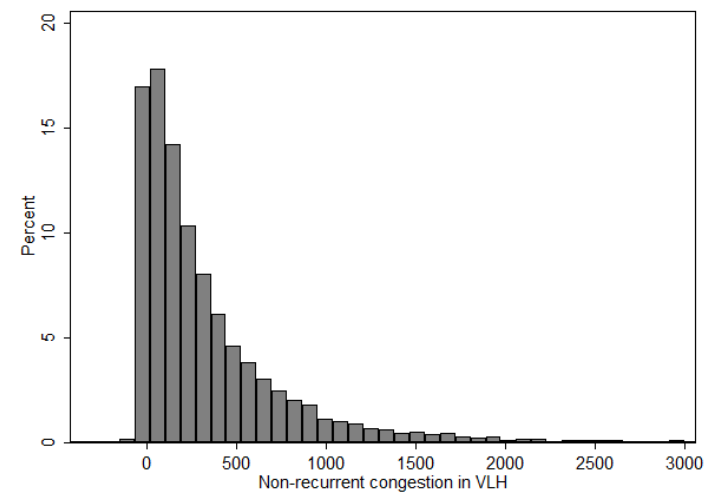

Figure 3 - Density of incident duration

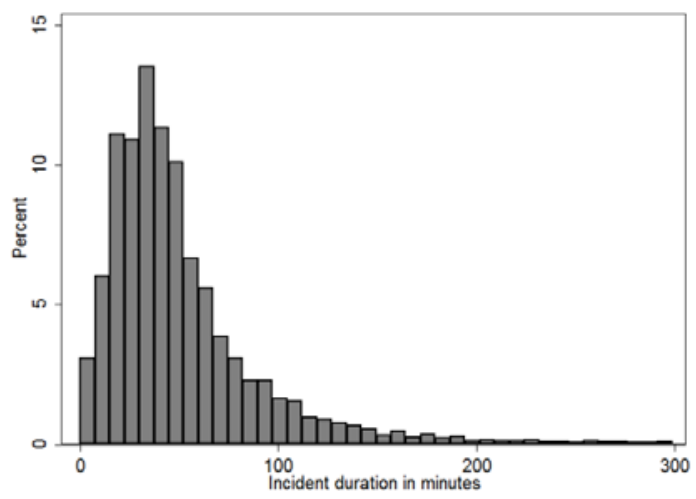

Figure 2- Density of recurrent congestion



In the selected data set, accidents are similar to non-accidents in terms of average incident duration (46 and 49 minutes respectively) and recurrent congestion (94 and 104 VLH, respectively), but average levels of non-recurrent congestion are about 25\% higher for accidents (450 and $361 \mathrm{VLH}$, respectively), see Table 1, (1) and (2). This table also shows that, by definition, incidents do not involve any damage or injuries, whereas about $36 \%$ of accidents involve fatalities, injuries or severe material damage.

\footnotetext{
${ }^{11}$ For example, in the selected data set $68 \%$ of incidents are accidents whereas in the full data set it is $39 \%$.

${ }^{12}$ Later on, we use a Heckman selection approach to deal with non-random data selection. The instrument used will depend on the source that reported the incident to RWS.

${ }^{13}$ For example, an incident (e.g., car break down) during the night on an empty highway will receive less attention from road service agencies than a fatal accident during rush hour on a congested highway.
} 
Recurrent and non-recurrent congestion follow approximately an exponential distribution, so low values are more common than high values, see Figures 1 and 2. For example, the maximum of recurrent congestion in our data is 4,271 VLH which is 40 times larger than the average value of $101 \mathrm{VLH}$. In our data the variation in recurrent congestion between locations is much larger than the within variation over time. Hence, it is useful to label locations with larger levels of congestion as 'congested locations'. Accordingly, in the analysis of the incident duration effect later, we will distinguish between locations with average recurrent congestion and congested locations. Incident duration is approximately lognormal distributed (see Figure 3), and durations up to 100 minutes are particularly common. Figure 4 shows a positive, concave relationship between incident duration and non-recurrent congestion. ${ }^{14}$ This positive effect is particularly clear for incident durations of less than 100 minutes (about $90 \%$ of observations).

Figure 4 - Non-recurrent congestion to incident duration

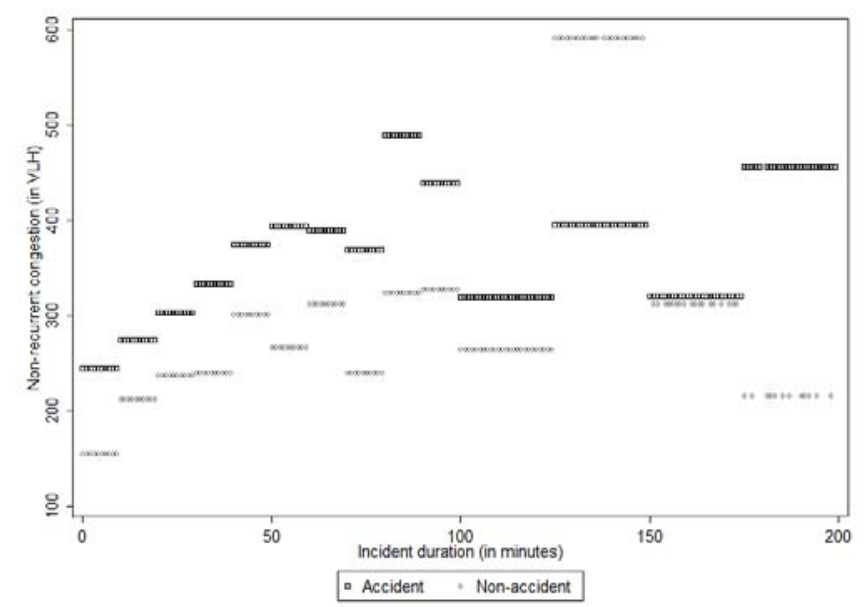

\section{Method}

To estimate the effect of incident duration on non-recurrent highway congestion, we estimate a log-linear specification for the 6,506 observations where recurrent congestion is positive. ${ }^{15}$ Hence, we assume that the logarithm of non-recurrent congestion, $N R C_{i, t}$, at location $i$ and time $t$, depends on the logarithm of recurrent congestion, $R C_{i, t}$, the logarithm of incident duration, $I D_{i, t}$, controls, $X_{i, t}$, location fixed effects, $a_{i}$, and an error term, $u_{i, t}$ :

$$
\log N R C_{i, t}=\beta \log R C_{i, t}+\gamma \log I D_{i, t}+\delta X_{i, t}+a_{i}+u_{i, t}
$$

\footnotetext{
${ }^{14}$ In this figure, incident duration is provided in intervals of 10 minutes for values below 100 minutes and in intervals of 25 minutes for values above 100 minutes. A few observations with durations that exceed 200 are excluded here.

${ }^{15}$ The logarithmic specification is most in line with the data. Later on, we also estimate a linear specification where we include locations with zero recurrent congestion (see, column 4 in Table 1).
} 
We are particularly interested in the marginal effect of incident duration on non-recurrent congestion. Given the log-linear specification, the marginal effect of incident duration is:

$$
\frac{\partial \mathrm{NRC}_{\mathrm{i}, \mathrm{t}}}{\partial \mathrm{ID}_{\mathrm{i}, \mathrm{t}}}=\gamma \frac{N R C_{i, t}}{I D_{i, t}}=\gamma \frac{R C_{i, t}{ }^{\beta} z_{i, t}}{I D_{i, t}^{1-\gamma}}
$$

where $z_{i, t}=\exp \left(\delta X_{i, t}+a_{i}+u_{i, t}\right)$. Because we will demonstrate that $\beta>0$, this implies that the marginal benefit increases with the level of recurrent congestion, so there is a multiplicative effect of incident duration and recurrent congestion.

We estimate equation (1) separately for accidents and non-accidents to allow for the possibility of a difference in their determinants. We control for accident severity (e.g. fatality), car type involved (e.g. truck) and weather. ${ }^{16}$ In addition, we include hour of the day, week(-end), month and year dummies and also include location fixed effects. For the main results, we use $100 \mathrm{~m}$ location fixed effects for accidents and $1 \mathrm{~km}$ location fixed effects for non-accidents (we use fewer location fixed effects for non-accidents because of fewer nonaccidents observations, which allows for sufficient degrees of freedom to estimate the effects we are interested in).

One may argue that incident duration is endogenous because congestion may block road service providers and therefore increase incident duration. However, this argument does not apply in the Netherlands, because incident management crew and first-response vehicles have access to emergency lanes (and may approach incident location in opposite direction of the traffic), which allows them to travel unhindered. ${ }^{17}$ Therefore, reverse causality is not a major concern.

We account for two other possible endogeneity problems: omitted variable bias and selection bias. First, heterogeneity in location, in terms of number of lanes, and proximity to on- and off-ramps may determine non-recurrent congestion. As stated above, we control for this unobserved heterogeneity in locations by using location fixed effects. Second, we account for data set selection bias with a Heckman correction two-step estimation approach (Heckman, 1979). In the selection equation, we use an instrument that directly affects the probability of incident duration being reported, but is unlikely to affect non-recurrent

\footnotetext{
${ }^{16}$ Temperature and maximum wind gust in the past hour are recorded hourly at the national level (in a central location of the Netherlands). Precipitation is measured within $1 \mathrm{~km}^{2}$ of the incident location for intervals of 90 minutes (30 minutes before and 60 minutes after the incident registration). Furthermore, we construct a dummy for falling snow (the interaction of precipitation and temperature below zero degrees Celsius).

${ }^{17}$ They may also travel through the middle of two lanes as cars have opened up space as required by law.
} 
congestion directly. ${ }^{18}$ So, the source that reported the incident is used as an instrument that distinguishes between police, incident management personnel and other source. One technical difficulty is the large number of location fixed effects because this approach is non-linear and cannot be estimated with 4,553 fixed effects. For this reason, when using the Heckman correction approach we use $5 \mathrm{~km}$ location dummies. The Heckman model results are very similar to the location fixed effects model that does not correct for selection effects. Hence, we focus on the latter.

Another issue is measurement error. Our construction of non-recurrent congestion is based on the measurement of recurrent congestion. It is likely that recurrent congestion has some measurement error (e.g., the median value is not representative for the true value of recurrent congestion). In this case, non-recurrent congestion, which is calculated using the difference between total and recurrent levels, will have measurement error which is negatively correlated to the measurement error of recurrent congestion. This implies that the effect of recurrent congestion might be negatively biased, so we likely somewhat underestimate the causal effect of recurrent congestion.

\section{Estimation results}

Table 2 shows the main results. For accidents, the incident duration elasticity of non-recurrent congestion is 0.43 , see column (1). This estimate implies that an incident duration increase of one minute (about two percent of the mean duration) results on average in an increase in nonrecurrent congestion of $3.95 \mathrm{VLH}$ (0.86 percent of the mean recurrent congestion). Assuming a VLH monetary value of $€ 20$, which is in line with the literature, this implies that one minute of incident duration costs about $€ 79 .{ }^{19}$ For non-accidents, this elasticity is 0.32 , see column (2), so about one-third lower than for accidents. Hence, one minute increase in non-accident duration leads to an increase of $2.34 \mathrm{VLH}$, equivalent to $€ 47$. Despite this difference, it appears that the elasticities of the accident and non-accident specification are not different at the $5 \%$ significance level $(\mathrm{t}=1.88)$. So, for our welfare calculations, we will not distinguish between the durations effects of accidents and non-accidents. ${ }^{20}$ Similarly, the estimated

\footnotetext{
${ }^{18}$ Hence, the source that reported the incident is assumed to be independent of non-recurrent congestion (conditional on controls), but the source affects the probability that the incident duration is reported in our data.

${ }^{19}$ There is a range of monetary values of travel time in the literature, see, for example, Calfee and Winston (1998) and Lam and Small (2001). Given an average occupancy of 1.6 persons per car, we implicitly use a value of time of $€ 12.5$ per person.

${ }^{20}$ Accidents are a small part of overall incidents but the main cause of non-recurrent congestion, according to Jones et al. (1991). In our case, because of the larger share of non-accidents and the similar elasticities, we arrive at the opposite conclusion.
} 
recurrent congestion elasticities for accidents and non-accidents are almost identical (0.25 and 0.30 respectively, $t=1.93)$.

Table 2 -Non-recurrent congestion

\begin{tabular}{|c|c|c|c|c|c|c|}
\hline \multirow[b]{4}{*}{ Incident duration (log) } & \multicolumn{3}{|c|}{ (1) } & \multicolumn{3}{|c|}{ (2) } \\
\hline & \multicolumn{3}{|c|}{ Accidents } & \multicolumn{3}{|c|}{ Non-accidents } \\
\hline & \multicolumn{2}{|c|}{ Coefficient } & \multirow{2}{*}{$\begin{array}{c}\text { Standard error } \\
0.039\end{array}$} & \multicolumn{2}{|c|}{ Coefficient } & \multirow{2}{*}{$\begin{array}{c}\text { Standard error } \\
0.045\end{array}$} \\
\hline & 0.429 & $* * *$ & & 0.317 & $* * *$ & \\
\hline Recurrent congestion (log) & 0.252 & $* * *$ & 0.016 & 0.303 & $* * *$ & 0.021 \\
\hline Injury and Fatality & 0.055 & & 0.095 & & & \\
\hline Material Damage (severe) & 0.039 & & 0.056 & & & \\
\hline Passenger car & 0.101 & & 0.063 & -0.028 & & 0.068 \\
\hline Truck & -0.033 & & 0.063 & -0.052 & & 0.088 \\
\hline Motorcycle & 0.216 & & 0.183 & 0.270 & & 0.343 \\
\hline Snow & -0.379 & & 0.669 & 1.279 & $* * *$ & 0.469 \\
\hline Max. wind gust (in m/sec) & 0.005 & & 0.008 & -0.009 & & 0.010 \\
\hline $\begin{array}{l}\text { Rain (in mm/hour) } \\
0 \text { to } 2.5\end{array}$ & 0.098 & & 0.070 & 0.262 & $* * *$ & 0.075 \\
\hline Above 2.5 & -0.407 & & 0.245 & 0.631 & $* *$ & 0.274 \\
\hline $\begin{array}{l}\text { Temperature (in degree Celsius) } \\
0 \text { to } 10\end{array}$ & -0.161 & & 0.147 & -0.007 & & 0.157 \\
\hline 10 to 20 & -0.115 & & 0.167 & 0.169 & & 0.189 \\
\hline Above 20 & -0.265 & & 0.190 & 0.177 & & 0.219 \\
\hline Location-fixed-effects & \multicolumn{3}{|c|}{$100 \mathrm{~m}$} & \multicolumn{3}{|c|}{$1 \mathrm{~km}$} \\
\hline $\begin{array}{l}\text { Year, month, hour and weekday of } \\
\text { observation }\end{array}$ & \multicolumn{3}{|c|}{ Included } & \multicolumn{3}{|c|}{ Included } \\
\hline $\mathrm{R}^{2}$ within & \multicolumn{3}{|c|}{0.3327} & \multicolumn{3}{|c|}{0.2953} \\
\hline $\mathrm{R}^{2}$ overall & \multicolumn{3}{|c|}{0.2808} & \multicolumn{3}{|c|}{0.2290} \\
\hline Number of fixed-effects & \multicolumn{3}{|c|}{4,553} & \multicolumn{3}{|c|}{1,139} \\
\hline Number of observations & \multicolumn{3}{|c|}{6,506} & \multicolumn{3}{|c|}{2,788} \\
\hline
\end{tabular}

Note: The logarithm of non-recurrent congestion is the dependent variable. $* * *, * * * *$ imply $1,5,10 \%$ significance levels. Standard errors are robust.

Our results imply that there are substantial benefits of reducing incident duration. For example, a one-minute reduction of incident duration for all 135,000 annual highway incidents decreases non-recurrent congestion costs by $€ 8.1$ million. ${ }^{21}$ The marginal benefit of one minute reduction is then, on average, $€ 60$.

We emphasize that we report the average value and the value strongly depends on the level of recurrent congestion, because of the multplicative effect with incident duration (see equation (2)), therefore, the benefit of a reduction at a location with a larger recurrent congestion is much larger. For example, in our data, the average level is $100 \mathrm{VLH}$. At

\footnotetext{
${ }^{21}$ Because the incident duration elasticities of non-recurrent congestion for accidents and non-accidents are not statistically different, we use the weighted marginal average of 3.01 VLH (i.e. €60) for a one minute reduction.
} 
locations with 2000 VLH of recurrent congestion, our estimates imply that non-recurrent congestion is, on average, 2.1 times higher than the given average levels of non-recurrent congestion, implying that the marginal benefit of reducing incident duration is 2.1 times higher (€126) than the average. ${ }^{22}$ Therefore, Incident Management policies should prioritize locations according to recurrent congestion to minimize non-recurrent congestion costs. ${ }^{23}$

We re-estimate the model for a quadratic specification of incident duration (no logarithms). We do this for the data set that excludes and for the data set that includes recurrent congestion observations that are zero (the descriptives are reported in (1) and (3) of Table 1). For the former, the point estimate of incident duration of accidents equals 4.630 and the point estimate of its square is -0.004 . For the latter, the point estimate equals 3.677 and the point estimate of its square is -0.003 (these coefficients are all significant at the $1 \%$ significance level). The marginal effects of accident duration are then 4.238 and 3.389 respectively (evaluated at the mean values). This translates to an accident duration elasticity of non-recurrent congestion of 0.47 and 0.38 respectively, which is similar to the results reported in Table 2. Therefore, this elasticity is robust over different specifications and data selections.

The estimated negative effect of the quadratic term of incident duration indicates that the effect on non-recurrent congestion is concave (consistent with Figure 4). ${ }^{24}$ Therefore, the marginal effect is the highest just after the incident occurs and becomes less for longer durations. One possible reason for this concave effect is the effect of traffic information, rerouting and other incident management activities. For example, dissipation of traffic information about the incident-induced non-recurrent congestion to road participants may result in a decrease of inflow of cars. Other examples include, incident management personnel clearing the road, thereby restoring road capacity, better assessment of incident situation translating in better road management (i.e. speed reduction). ${ }^{25}$ It might be that without (or with different) incident management policy and/or traffic information systems (i.e., in other countries), this effect is linear or even convex. For example, economic theory suggests that in a stylized case without rerouting and inelastic demand for travel, there is a quadratic effect of

\footnotetext{
${ }^{22}$ Note that $(2000 / 100)^{0.252}=2.1$.

23 After 2009 this has been acknowledged by RWS (Immers et al., 2008), where incident management crews response times are required to be less for locations with high levels of recurrent congestion.

${ }^{24}$ We have also estimated models with a flexible dummy specification of incident duration. These models also show that the effect is concave.

${ }^{25}$ One can imagine that heavier incidents with longer durations trigger a stronger response from incident management crews reducing non-recurrent congestion. This interpretation is however conflicting with our result that incident characteristics and severity do not play a significant role in explaining non-recurrent congestion.
} 
incident duration of non-recurrent congestion (Hall, 1993; Koster and Rietveld, 2011) suggesting that the elasticity would be 2 rather than values around 0.40 as reported by us.

We have noticed above that at more congested locations the benefit of a reduction in the incident duration is larger (as implied by the specification in logarithms). However, it is also plausible that the effects of logarithm recurrent congestion and logarithm incident duration interact. We address this issue for accidents. The results are reported in (1) of Table 3. We find a slight positive interaction effect but it is only significant at a $10 \%$ significance level.

Another way to address this issue is by excluding the large number of locations where recurrent congestion levels are low. Therefore, we re-estimate the model for accidents at locations with recurrent congestion above 5VLH (62\% of our observations). The accident duration and recurrent congestion elasticities both increase by roughly 20\%, as shown in column (2). This is consistent with the small positive interaction effect reported in column (1).

Table 3 - Non-recurrent congestion of accidents

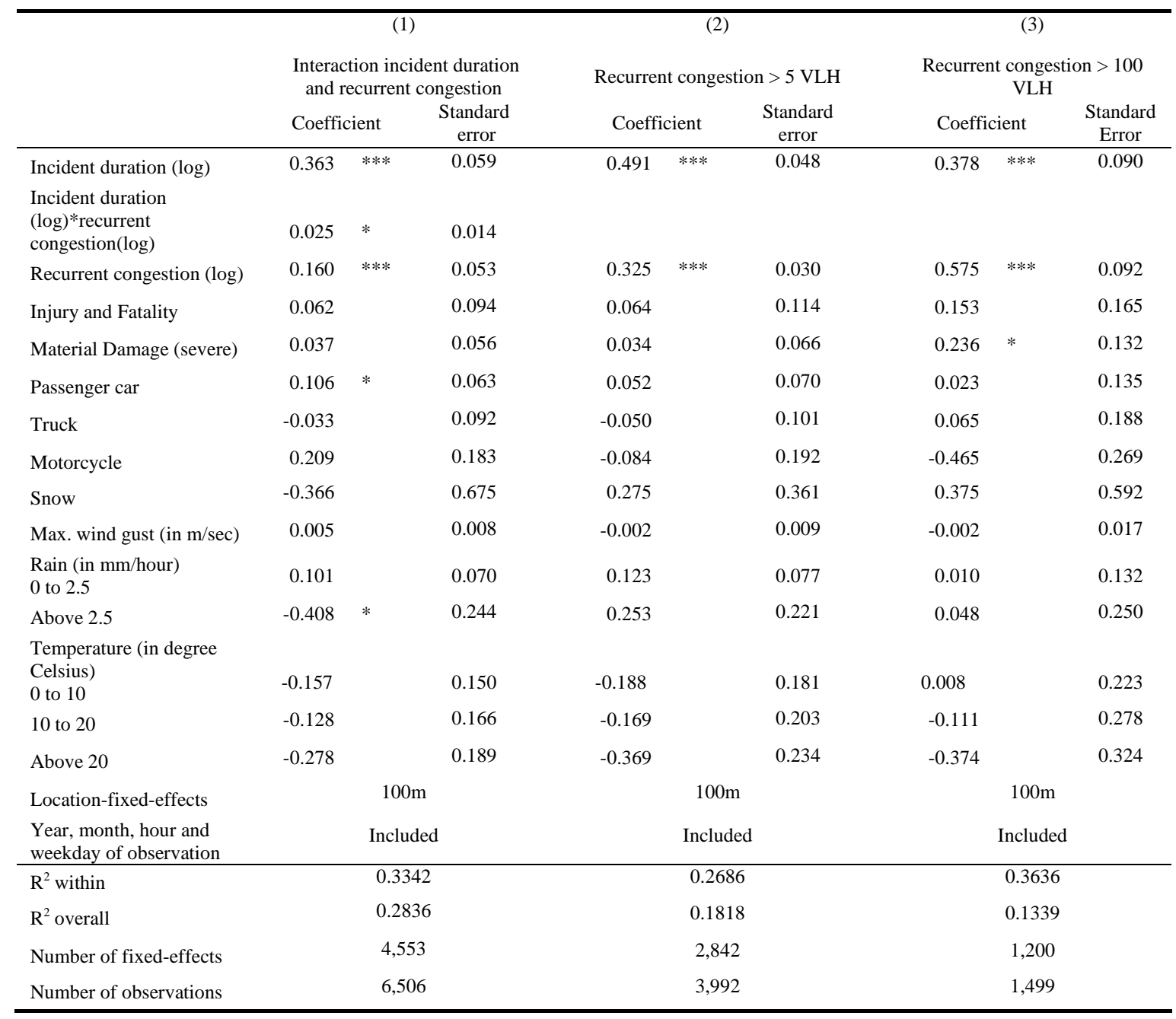

Note: In all three models, the logarithm of non-recurrent congestion is the dependent variable. ***, **,* imply $1,5,10 \%$ significance levels. All standard errors are robust. 
Further evidence of this is provided in (3) of Table 3 where we restrict the data to congested locations with recurrent congestion above the average value of $100 \mathrm{VLH}$. The recurrent congestion elasticity doubles to 0.575 , but the incident duration elasticity remains similar to the original estimate (see (1) of Table 2). Therefore, the incident duration elasticity is robust over different data set selections and over different model specifications, whereas the recurrent congestion elasticity is larger for congested locations. According to (3) in Table 3 at very congested locations (with $4000 \mathrm{VLH}$ of recurrent congestion), the marginal effect of incident duration is 8.3 times larger than the marginal effect where the recurrent congestion is equal to the average, so a one minute duration costs about $€ 500 .^{26}$ This reinforces our conclusion that Incident Management policies should prioritize those congested locations. Note that our estimate is low in comparison to the $\$ 2000$ of Garrison and Mannering (1990) who also focus on congested locations but who consider a major urban highway with a severe incident that reduces capacity by $75 \%$ during rush hour. Our $€ 500$ refers to the average effect of incident duration for congested locations, irrespective of the numbers of lanes closed and irrespective of the hour of the day.

Non-recurrent congestion is not the only component of incident welfare losses. Another component is time loss due to rerouting. In case the incident duration is long and congestion levels are high, so expected time loss in the queue is long, it may be beneficial for drivers to make a detour that increases their travel time costs but reduces their time in the queue. ${ }^{27}$ In our data, drivers' average delay in the queue is $18 \%$ to $25 \%$ of incident duration (because most of the time not all lanes are closed). ${ }^{28}$ Hence, it is plausible that drivers make only a detour for very long incident durations (i.e. longer than an hour).

The additional costs of an incident vary with the number of road users who make a detour, which depends on the availability of route alternatives (e.g., a link to another highway) and information to the road user about the occurrence of the incident. According to the Wardrop (1952) principle, when drivers are well-informed, a certain proportion of drivers decide to make a detour so that in the end the travel time for those who stay in the queue and

\footnotetext{
${ }^{26}$ Note that $(4000 / 100)^{0.575}=8.3$.

${ }^{27}$ The average distance between two highways is $13.2 \mathrm{~km}$ for the most frequented urban area (i.e. Randstad). In the Netherlands, highways have predominantly replaced the pre-existing provincial road network, so usually taking a detour on another highway is the only reasonable alternative. If road users choose the route alternative that minimizes (expected) travel time, the detour time has to be equal to or less than, the congestion delay. So only for very long incident duration drivers consider detours.

${ }^{28}$ This is calculated as follows. For incidents longer than one hour the non-recurrent congestion average is $880 \mathrm{VLH}$. The drivers delay is then between $880 / 4800=18 \%$ (for a four-lane highway with 4,800 vehicles per hour) and $880 / 3600=25 \%$ (for a three-lane highway with 3,600 vehicles per hour) at congested locations.
} 
those who make a detour is the same. ${ }^{29}$ In the Netherlands, around $20 \%$ of road users choose to detour if they have been informed on a delay of one hour (Peer, 2013). The results by Emmerink et al. (1996) suggest a similar percentage. Assuming this percentage to be true, we may underestimate the total welfare loss (i.e. the sum of non-recurrent congestion and detour time costs) by up to $25 \%$ at very congested locations with long incident durations. So, on average, detour time cost adds much less than $25 \%$ to the overall welfare costs. ${ }^{30}$ Note that in addition to rerouting there are other behavioural responses such as rescheduling of activities that imply welfare losses that are not included here.

Incident characteristics (e.g. injury, truck involved) are an explanatory factor of incident duration, as shown, for example by Guiliano (1989) and Nam and Mannering (2000). ${ }^{31}$ When controlling for $100 \mathrm{~m}$ location fixed effects and incident duration the effect of accident characteristics is insignificant. Therefore, incident duration is the important factor in explaining non-recurrent congestion and captures the effects of the other accident characteristics - vehicle type and severity. ${ }^{32}$ Weather conditions do not seem to affect accident non-recurrent congestion, but precipitation increases non-recurrent congestion of nonaccidents. $^{33}$

\section{Sensitivity Analyses}

We conduct several sensitivity analyses of the results. We focus here on the accidents for which we have more observations. First, we increase the location-fixed-effects group variable to $1 \mathrm{~km}$ (see Table 4, (1)) as well as to $5 \mathrm{~km}$ (Table A2, (2) in the Appendix), and estimate models without controlling for location fixed effects (see Table 4 , (2)). ${ }^{34}$ The effects of incident duration and recurrent congestion are very similar in size with those discussed before. So, our main results are not sensitive to the inclusion of the definition of fixed effects.

\footnotetext{
${ }^{29}$ Note that by making the detour, the latter reduce the waiting time of those who continue to wait in the queue.

${ }^{30}$ Of the $100 \%$ of drivers affected by an incident, $80 \%$ do not change route and $20 \%$ make a detour. Using the Wardrop principle, the travel time loss of the group that changes route is $20 / 80=25 \%$ of the group that does not change route. This would imply an extra welfare loss of $25 \%$.

${ }^{31}$ We also estimated the effect of incident characteristics on non-recurrent congestion without including incident duration. The effects of many characteristics become then significant (results are not shown here). We also estimated models on incident duration as a function of incident characteristics, time of day, week, month, year and weather. These results are similar to those found in Vukovic et al. (2013).

${ }^{32}$ However, when using less location fixed effects or not controlling for fixed effects some of the accident characteristics become significant.

${ }^{33}$ For example, the presence of snow strongly increases non-recurrent congestion. The effect of snow and heavy rain between recurrent and non-recurrent congestion cannot be disentangled here because we do not observe the weather for recurrent congestion.

${ }^{34}$ The location precision level decrease may result in introducing unobserved heterogeneity bias. For example, a $1 \mathrm{~km}$ road segment with an on- and off-ramp in front of the accident could change the resulting non-recurrent congestion because of the possibility of re-routing. Also, incident clearance, number of lanes, and other factors could be non-homogenous in space.
} 
Second, for the Heckman correction model (see (1) of Table A2, in the Appendix), the elasticities of incident duration and recurrent congestion are almost identical to the results dicsussed above. ${ }^{35}$

Table 4 - Sensitivity Analysis- Non-recurrent congestion of accidents

\begin{tabular}{|c|c|c|c|c|c|c|c|c|c|}
\hline \multirow[b]{4}{*}{ Incident duration (log) } & \multicolumn{3}{|c|}{ (1) } & \multicolumn{3}{|c|}{ (2) } & \multicolumn{3}{|c|}{ (3) } \\
\hline & \multicolumn{3}{|c|}{$1 \mathrm{~km}$ location } & \multicolumn{3}{|c|}{ No location control } & \multicolumn{3}{|c|}{$\begin{array}{l}\text { Recurrent congestion not } \\
\text { included }\end{array}$} \\
\hline & \multicolumn{2}{|c|}{ Coefficient } & \multirow{2}{*}{$\begin{array}{c}\begin{array}{c}\text { Standard } \\
\text { error }\end{array} \\
0.028\end{array}$} & \multicolumn{2}{|c|}{ Coefficient } & \multirow{2}{*}{$\begin{array}{c}\text { Standard } \\
\text { error }\end{array}$} & \multicolumn{2}{|c|}{ Coefficient } & \multirow{2}{*}{$\begin{array}{c}\begin{array}{c}\text { Standard } \\
\text { error }\end{array} \\
0.043\end{array}$} \\
\hline & 0.406 & $* * *$ & & 0.370 & $* * *$ & & 0.447 & $* * *$ & \\
\hline Recurrent congestion (log) & 0.236 & $* * *$ & 0.113 & 0.204 & $* * *$ & 0.007 & & & \\
\hline Injury and Fatality & 0.161 & $* * *$ & 0.059 & 0.150 & $* * *$ & 0.058 & 0.011 & & 0.102 \\
\hline Material Damage (severe) & 0.109 & $* * *$ & 0.037 & 0.115 & $* * *$ & 0.037 & 0.067 & & 0.060 \\
\hline Passenger car & 0.090 & $* *$ & 0.043 & 0.239 & $* * *$ & 0.042 & 0.115 & & 0.071 \\
\hline Truck & 0.065 & & 0.061 & 0.102 & $*$ & 0.057 & -0.049 & & 0.102 \\
\hline Motorcycle & 0.255 & $* *$ & 0.111 & 0.202 & $*$ & 0.118 & 0.360 & $*$ & 0.199 \\
\hline Snow & -0.043 & & 0.474 & 0.433 & & 0.462 & -0.512 & & 0.707 \\
\hline Max. wind gust (in m/sec) & 0.007 & & 0.006 & 0.005 & & 0.005 & 0.001 & & 0.008 \\
\hline $\begin{array}{l}\text { Rain (in mm/hour) } \\
0 \text { to } 2.5\end{array}$ & 0.096 & $* *$ & 0.042 & 0.082 & $* *$ & 0.041 & 0.135 & $*$ & 0.076 \\
\hline Above 2.5 & -0.436 & $* *$ & 0.022 & -0.399 & $*$ & 0.217 & -0.435 & & 0.300 \\
\hline $\begin{array}{l}\text { Temperature (in degree } \\
\text { Celsius) } \\
0 \text { to } 10\end{array}$ & -0.434 & & 0.104 & 0.018 & & 0.104 & -0.246 & & 0.168 \\
\hline 10 to 20 & 0.020 & & 0.113 & 0.083 & & 0.115 & -0.189 & & 0.190 \\
\hline Above 20 & -0.119 & & 0.126 & 0.014 & & 0.129 & -0.226 & & 0.214 \\
\hline Location-fixed-effects & \multicolumn{3}{|c|}{$1 \mathrm{~km}$} & \multicolumn{3}{|c|}{ Not included } & \multicolumn{3}{|c|}{100 meters } \\
\hline $\begin{array}{l}\text { Year, month, hour and } \\
\text { weekday of observation }\end{array}$ & \multicolumn{3}{|c|}{ Included } & \multicolumn{3}{|c|}{ Included } & \multicolumn{3}{|c|}{ Included } \\
\hline $\mathrm{R}^{2}$ (within) & \multicolumn{3}{|c|}{0.3217} & \multicolumn{3}{|c|}{0.3167} & \multicolumn{3}{|c|}{0.1915} \\
\hline $\mathrm{R}^{2}$ overall & \multicolumn{3}{|c|}{0.3066} & & & & \multicolumn{3}{|c|}{0.1397} \\
\hline Number of fixed-effects & \multicolumn{3}{|c|}{1,680} & & & & \multicolumn{3}{|c|}{4,553} \\
\hline Number of Observation & \multicolumn{3}{|c|}{6,506} & \multicolumn{3}{|c|}{6,506} & \multicolumn{3}{|c|}{6,506} \\
\hline
\end{tabular}

Note: In all three models, the logarithm of non-recurrent congestion is the dependent variable. ***, **** imply $1,5,10 \%$ significance levels. Standard errors are robust.

Third, we re-estimate the model not controlling for recurrent congestion. The results ((3) in Table 4) show that the incident duration elasticity estimate is then biased upwards. Therefore, controlling for recurrent congestion is important to obtain consistent estimates of effect of incident duration on non-recurrent congestion.

\footnotetext{
${ }^{35}$ It also appears that our instrument is highly statistically significant and has the expected effect on the probablitiy of reporting incident duration. We find that when the police is the source of reporting the duration is more likely to be reported. One possible explanation is that when the police reports the incident to the traffic control regional office, traffic measures (e.g., speed reduction) are more likely to be applied, which increases the probability that incident duration is observed and recorded. In contrast, when incident management crews are the first to report the incident, the duration might not be recorded because the crew is busy dealing with the incident and does not request traffic measures.
} 


\section{Conclusion}

Our estimates show that incident duration substantially increases the level of non-recurrent congestion on highways. The incident duration elasticity of non-recurrent congestion is about 0.40 and similar for accidents and non-accidents. This implies that one marginal minute incident duration costs about $€ 60$ per incident. The annual economic value of one marginal minute incident duration reduction is then $€ 8.1$ million for the Netherlands. In addition, we show that the marginal effect of incident duration on non-recurring congestion is diminishing. Therefore, incident management policies should focus on reducing all durations, not in particular the longer ones.

Furthermore, recurrent congestion has a strong positive effect on non-recurrent congestion. Recurrent congestion and incident duration have a multiplicative effect on nonrecurrent congestion. This implies that incident management policy should focus on locations with larger recurrent congestion levels, because there the reduction in incident duration has a larger impact. For very congested locations the marginal cost of one minute duration is about $€ 500$ per incident. Including other aspects of incident management policies in the future research, such as the type of road measures applied, may increase our understanding of the effect of incident management on welfare. 


\section{Appendix}

Figure A1- National Dutch highway network

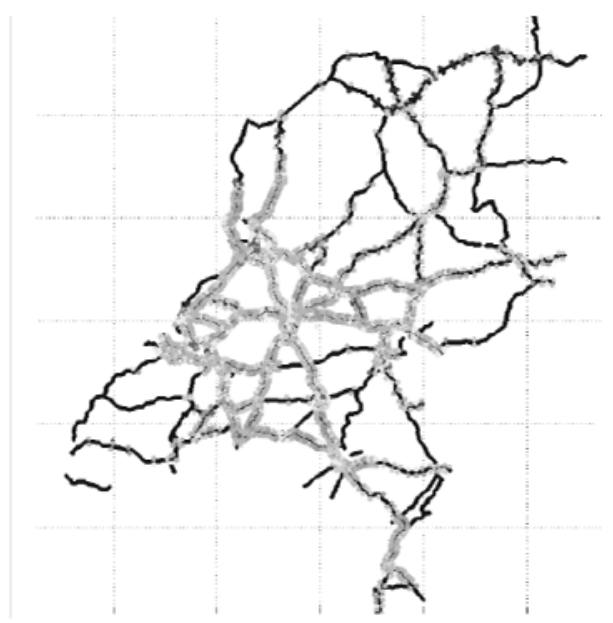

Source: Vukovic et. al., 2013

Table A1 - Recurrent congestion matrix

\begin{tabular}{|c|c|c|c|c|c|c|c|c|c|}
\hline & \multicolumn{9}{|c|}{ Time in Weeks } \\
\hline & -4 & -3 & -2 & -1 & & +1 & +2 & +3 & +4 \\
\hline \multirow[t]{3}{*}{ Weekdays } & & & & & $\begin{array}{l}\text { Monday } \\
\text { Tuesday } \\
\text { Wednesday } \\
\text { Thursday }\end{array}$ & & & & \\
\hline & Friday & Friday & Friday & $\begin{array}{l}\text { Friday } \\
\text { weighted }\end{array}$ & Friday (F) & $\begin{array}{l}\text { Friday } \\
\text { weighted }\end{array}$ & Friday & Friday & Friday \\
\hline & & & & & $\begin{array}{l}\text { Saturday } \\
\text { Sunday }\end{array}$ & & & & \\
\hline
\end{tabular}

Note: Here, the incident is on a Friday (in grey). Recurrent congestion values of the Friday one week before and after the incident receive a weight of two. 
Table A2 - Heckman selection model for logarithm of accident non-recurrent congestion

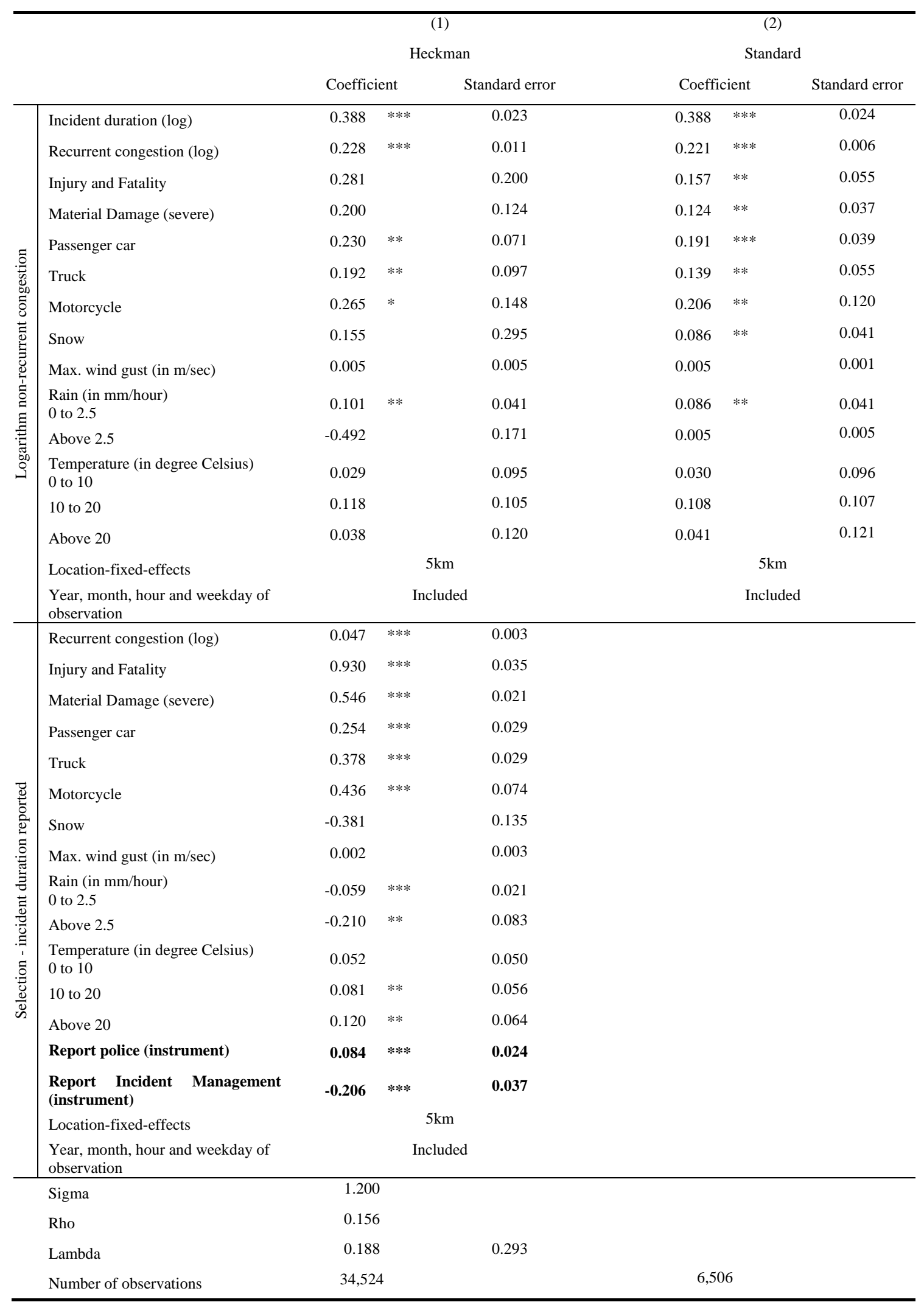

Note: In both models the logarithm of non-recurrent congestion is the dependent variable. Standard errors are robust. ***, **,* imply 1, 5, 10\% significance levels. 


\section{References}

Arnott, R. \& Small, K. (1994). The economics of traffic congestion. American Scientist, 82(5), 446-455.

Beckmann, M. J., McGuire, C. B. \& Winsten, C. B. (1956). Studies in the Economics of Transportation. Oxford University Press.

Calfee, J. \& Winston, C. (1998). The value of automobile travel time: implications for congestion policy. Journal of Public Economics, 69(1), 83-102.

Carson, J. L., Mannering, F. L., Legg, B., Nee, J. \& Nam, D. (1999). Are incident management programs effective? Findings from Washington State. Transportation Research Record: Journal of the Transportation Research Board, 1683(1), 8-13.

Downs, A. (2004). Still Stuck in Traffic: Coping with Peak-Hour Traffic Congestion. Brookings Institution Press.

Emmerink, R. H., Nijkamp, P., Rietveld, P. \& Van Ommeren, J. N. (1996). Variable message signs and radio traffic information: An integrated empirical analysis of drivers' route choice behavior. Transportation Research Part A: Policy and Practice, 30(2), 135-153.

Jones, B., Janssen, L., \& Mannering, F. (1991). Analysis of the frequency and duration of freeway accidents in Seattle. Accident Analysis \& Prevention, 23(4), 239-255.

Garrison, D. \& Mannering, F. (1990). Assessing the traffic impacts of freeway incidents and driver information. ITE Journal, 60(8), 19-23.

Guiliano, G. (1989). Incident characteristics, frequency, and duration on a high volume urban freeway. Transportation Research Part A: General, 23(5), 387-396.

Goodwin, P. (2004). The Economic Cost of Road Congestion. University College London. The Rail Freight Group.

Hall, R. W. (1993). Non-recurrent congestion: how big is the problem?: are traveler information systems the solution? Transportation Research C. (1): 89-103.

Heckman, J. J. (1979). Sample selection bias as a specification error. Econometrica, 153-161.

Immers, B. \& Landman, R. (2008). "SMART" Goals for the Application of Incident Management Measures to the Dutch Road Network. TNO.

Jones, B., Janssen, L. \& Mannering, F. (1991). Analysis of the frequency and duration of freeway accidents in Seattle. Accident Analysis and Prevention, 23(4): 239-255.

Koster, P. \& Rietveld, P. (2011). Optimising Incident Management on the Road. Journal of Transport Economics and Policy, 45(1): 63-81.

Lam, T. C. \& Small, K. A. (2001). The value of time and reliability: measurement from a value of pricing experiment. Transportation Research Part E, 34A, 85-102. 
Nam, D., \& Mannering, F. (2000). An exploratory hazard-based analysis of highway incident duration. Transportation Research Part A: Policy and Practice, 34(2), 85-102.

Peer, S. (2013). The Economics of Trip Scheduling Travel Time Variability and Traffic Information. Vrije Universiteit, Amsterdam.

Sabir, M. (2011). Weather and Travel Behavior. Vrije Universiteit, Amsterdam.

Small, K. A. \& Verhoef, E. (2007). The Economics of Urban Transportation. Routledge.

Snelder, M. \& Drolenga, H. (2011). De Robuustheid van het Nederlandse Hoofdwegennet. TNO.

Vukovic, D., Adler, M. W \& Vonk, T. (2013). Neerslag en Verkeer. TNO.

Wardrop, J. G. (1952). Road paper. Some theoretical aspects of road traffic research. In ICE Proceedings: Engineering Divisions, 1(3), 325-362, Thomas Telford.

Wooldridge, J. M. (2009). Introductory Econometrics: A Modern Approach. South-Western Pub. 